\title{
Cerebral and somatic oxygen saturation decrease after delayed sternal closure in children after cardiac surgery
}

\author{
Robert Horvath, MD, ${ }^{\mathrm{a}}$ Shirah Shore, MD, ${ }^{\mathrm{a}}$ Steven E. Schultz, MD, ${ }^{\mathrm{a}}$ Eliot R. Rosenkranz, MD, \\ Mary Cousins, ARNP, ${ }^{\mathrm{b}}$ and Marco Ricci, $\mathrm{MD}^{\mathrm{b}}$
}

\begin{abstract}
Objectives: Delayed sternal closure after pediatric cardiac surgery can temporarily impair cardiac output. Cerebral and somatic regional oxygen saturation measured by using near-infrared spectroscopy (NIRS) have been used as potential surrogates of cerebral and somatic mixed venous oxygen saturation. We hypothesized that cerebral and somatic regional oxygen saturation correlate with indicators of hemodynamic compromise after delayed sternal closure in children undergoing cardiac surgery.
\end{abstract}

\begin{abstract}
Methods: We studied 36 postoperative children (median age, 10 days; range, 1-510 days) undergoing delayed sternal closure $3.7 \pm 2$ days after cardiac surgery. Twenty-five had biventricular physiology, whereas 11 had single-ventricle physiology. Cerebral regional oxygen saturation, somatic regional oxygen saturation, and other physiologic parameters (hemodynamic data, respiratory data, blood gas analysis, lactate levels, and inotrope scores) were analyzed at 16 different time points 24 hours before and after sternal closure. One-way analysis of variance and the paired $t$ test were used for statistical comparisons.
\end{abstract}

Results: Cerebral and somatic regional oxygen saturation decreased after delayed sternal closure compared with preclosure levels $(P=.02$ and $P=.01$, respectively). Higher heart rate $(P=.03)$, lactate levels $(P=.02)$, and left atrial pressure $(P=.001)$ were also noted, suggesting mild hemodynamic compromise. Arterial pressure and inotrope score were unchanged. Somatic regional oxygen saturation returned to preclosure levels earlier in the biventricular group than in the single-ventricle group, whereas cerebral regional oxygen saturation remained decreased after sternal closure with no evidence of return to preclosure levels during the observation period. Oxygen saturation, $\mathrm{PaO}_{2}$, and $\mathrm{PaCO}_{2}$ levels were unaffected by sternal closure, although greater positive-pressure ventilation was required $(P<.01)$, suggesting reduced lung compliance.

Conclusion: Cerebral and somatic regional oxygen saturation decrease after delayed sternal closure in children recovering from congenital cardiac surgery. These indices are in agreement with other physiologic indicators of cardiac performance, suggesting mild and transient hemodynamic compromise after sternal closure. Cerebral and somatic regional oxygen saturation monitoring might be a useful adjunct during delayed sternal closure. (J Thorac Cardiovasc Surg 2010;139:894-900)

Delayed sternal closure has been used successfully in children undergoing complex cardiac procedures. ${ }^{1,2}$ Previous reports have shown that delayed sternal closure can result in a transient decrease in hemodynamic performance. ${ }^{1}$ Therefore delayed sternal closure could represent a period of relative brain and other end-organ vulnerability to reduced oxygen delivery.

Near-infrared spectroscopy (NIRS) is a noninvasive technique that monitors regional oxygen saturation $\left(\mathrm{rSO}_{2}\right)$ in the brain or other tissues by measuring the relative tissue con-

\footnotetext{
From the Divisions of Pediatric Cardiology ${ }^{\mathrm{a}}$ and Cardiothoracic Surgery, ${ }^{\mathrm{b}}$ University of Miami Leonard Miller School of Medicine and Holtz Children's Hospital/Jackson Memorial Hospital, Miami, Fla.

Disclosures: None.

Abstract read at the 2008 Annual Symposium of the Pediatric Cardiac Intensive care Society, Miami Beach, Fla, Dec 2-6, 2008.

Received for publication Jan 27, 2009; revisions received April 13, 2009; accepted for publication June 14, 2009; available ahead of print July 27, 2009.

Address for reprints: Marco Ricci, MD, Pediatric Cardiac Surgery, Holtz Children's Hospital/Jackson Memorial Hospital, University of Miami Miller School of Medicine, PO Box 016960 (R-114), Miami, FL 33136 (E-mail: mricci@med.miami.edu). $0022-5223 / \$ 36.00$

Copyright $(c) 2010$ by The American Association for Thoracic Surgery doi:10.1016/j.jtcvs.2009.06.013
}

centrations of oxyhemoglobin and deoxyhemoglobin. ${ }^{3}$ $\mathrm{rSO}_{2}$ has been used as surrogate indicator of mixed venous oxygen saturation. ${ }^{4}$ The value and limitations of this technology have been investigated in a variety of clinical ${ }^{5-9}$ and experimental ${ }^{10-12}$ situations but not in the setting of delayed sternal closure.

In this study we used NIRS technology to monitor cerebral and somatic (kidney) $\mathrm{rSO}_{2}$ values before and after delayed sternal closure in children undergoing surgical intervention for congenital heart disease. We hypothesized that changes in cerebral and somatic $\mathrm{rSO}_{2}$ values correlate with indicators of hemodynamic compromise after delayed sternal closure.

\section{MATERIALS AND METHODS Study Design}

The study was designed in such a way that preclosure physiologic and biochemical parameters were compared with postclosure parameters, with each patient serving as his or her own control subject. Children who received delayed sternal closure (study group) were not compared with those who received sternal closure in the operating room because in our 


\section{Abbreviations and Acronyms}

ANOVA $=$ analysis of variance

NIRS = near-infrared spectroscopy

$\mathrm{rSO}_{2} \quad=$ Regional oxygen saturation

program the vast majority of neonates (the dominant group in this study) are treated with delayed sternal closure.

After obtaining institutional review board approval, we retrospectively reviewed 36 children who underwent pediatric cardiac surgery from 2005 to 2008 in whom an open-chest approach was used. Those in whom postoperative $\mathrm{rSO}_{2}$ data had been monitored and were available for review were included in the study. The median age was 10 days (mean, 60 days; range, 1-510 days), and the relative age distribution was as follows: 28 neonates (0-1 month; 77\%), 6 infants (1-12 months; $16 \%)$, and 2 children $(>1$ year; $5 \%$ ).

All children were managed initially by using the open-chest approach followed by delayed sternal closure in the pediatric intensive care unit 3.7 \pm 2 days after cardiac surgery. Delayed sternal closure was routinely performed with fentanyl-induced anesthesia and a neuromuscular blocking agent. Neuromuscular blockade was discontinued after sternal closure in the majority of cases. Physiologic parameters and $\mathrm{rSO}_{2}$ trends were closely monitored after chest closure. The decision to reopen the chest was based on clinical and physiologic changes, as well as $\mathrm{rSO}_{2}$ trends, and not on any specific protocol.

\section{Data Collection and Statistical Analysis}

Standard postoperative monitoring included physiologic data (systemic arterial pressure, left atrial pressure, and urinary output), respiratory data $\left(\mathrm{PaO}_{2}, \mathrm{PaCO}_{2}\right.$, oxygen saturation, base excess, fraction of inspire oxygen $\left[\mathrm{FIO}_{2}\right]$, and respiratory $\Delta \mathrm{P}$ ), laboratory data (hemoglobin and lactate values), and inotrope score (dopamine, epinephrine, and milrinone). The inotrope score was calculated as follows:

Inotrope score $=($ Dopamine infusion rate $\times 1)+$

(Milrinone infusion rate $\times 10)+$

(Epinephrine infusion rate $\times 100$ ).

Cerebral $\mathrm{rSO}_{2}$, somatic $\mathrm{rSO}_{2}$, and other physiologic parameters (hemodynamic and respiratory data, blood gas analysis, lactate levels, and inotrope scores) were measured at 16 time points 24 hours before chest closure ( -24 hours, -18 hours, -12 hours, -6 hours, and -2 hours), at chest closure ( 0 hours), and after chest closure ( +1 hour, +2 hours, +3 hours, +4 hours, +5 hours, +6 hours, +8 hours, +12 hours, +18 hours, and +24 hours).

A commercially available device (INVOS 5100B Cerebral Oxymeter; Somanetics Corp, Troy, Mich) was used to monitor $\mathrm{rSO}_{2}$ values in the frontal cerebral cortex and in the right flank (right kidney area) during surgical intervention and throughout the postoperative period. This technology has been described previously. ${ }^{3}$ A $30-\mathrm{mm}$ patch containing the NIRS-emitting source and sensor was placed on the forehead and flank and connected to the infrared spectrophotometer unit. The NIRS probe measures cerebral $\mathrm{rSO}_{2}$ values by subtracting superficial light-scattering signals that originate from extracranial tissues. The device monitor displays data continuously, although for the statistical analysis, we used $\mathrm{rSO}_{2}$ data collected at selected time points.

Physiologic data were expressed as means \pm standard errors of the mean. One-way repeated-measures analysis of variance (ANOVA) was used to detect an increase or decrease in cerebral $\mathrm{rSO}_{2}$, somatic $\mathrm{rSO}_{2}$, and other physiologic data obtained at selected time points during the study. The 2-tailed paired $t$ test was also used to compare measurements obtained before and after chest closure.

\section{RESULTS}

Thirty-six children underwent cardiac surgery with delayed sternal closure (Table 1). Of these, 25 had biventricular physiology, and 11 had single-ventricle physiology (Table 2). Ten of the 11 children in the single-ventricle group had a stage 1 Norwood procedure (Table 2). Extracorporeal membrane oxygenation was used in 2 patients in this group in combination with the open-chest approach. Chest closure was successful in $34(94.4 \%)$ of the 36 patients, whereas chest reopening was required in 2 patients. Both patients had single-ventricle circulation and required chest reopening because of hemodynamic compromise approximately 1 and 30 hours after closure, respectively. In the patient who required reopening at 30 hours, $\mathrm{rSO}_{2}$ values decreased after closure and improved after the chest was reopened (Figure 1).

Changes in cerebral and somatic $\mathrm{rSO}_{2}$ values in the entire cohort are shown in Figure 2. Absolute values of $\mathrm{rSO}_{2}$ were lower in the single-ventricle group compared with those seen in the biventricular group, as expected because of the presence of physiologic hypoxemia. Cerebral and somatic $\mathrm{rSO}_{2}$ values decreased after sternal closure $(P=.02$ and $P=$ .01, 1-way ANOVA, respectively), whereas partial recovery was noted at +16 hours after sternal closure for somatic but not for cerebral $\mathrm{rSO}_{2}$ values. When cerebral $\mathrm{rSO}_{2}$ trends were analyzed separately in the biventricular and single-ventricle groups (Figure 3), we found that cerebral $\mathrm{rSO}_{2}$ values decreased after sternal closure in the biventricular group $(P=.04,1$-way ANOVA). In the single-ventricle group $\mathrm{rSO}_{2}$ changes were not statistically significant $(P=.2$, 1-way ANOVA), although cerebral $\mathrm{rSO}_{2}$ values were lower at +6 hours versus -6 hours, as shown in Figure $2(P=.02)$.

TABLE 1. Clinical variables of the patient population

\begin{tabular}{|c|c|c|c|}
\hline Variable & $\begin{array}{c}\text { Single-ventricle } \\
\text { group }\end{array}$ & $\begin{array}{c}\text { Biventricular } \\
\text { group }\end{array}$ & All patients \\
\hline No. of patients & 11 & 25 & 36 \\
\hline $\begin{array}{l}\text { Weight }(\mathrm{kg}) \text {, mean } \\
\text { (range) }\end{array}$ & $2.8(2-3.5)$ & $3.92(2-9)$ & $3.6(2-9)$ \\
\hline $\begin{array}{l}\text { Patient age (d) } \\
\text { mean (range) }\end{array}$ & $8.1(1-20)$ & $79.7(1-510)$ & $60.1(1-510)$ \\
\hline $\begin{array}{l}\text { Time of the } \\
\text { delayed sternal } \\
\text { closure (d), } \\
\text { means (range) }\end{array}$ & $5(2-8)$ & $3.2(1-8)$ & $3.7(1-8)$ \\
\hline Successful closure & $9 / 11(82 \%)$ & $25 / 25(100 \%)$ & $34 / 36(94 \%)$ \\
\hline $\begin{array}{l}\text { Sternal wound } \\
\text { infection }\end{array}$ & $1 / 11(9 \%)$ & $2 / 25(8 \%)$ & $3 / 36(8 \%)$ \\
\hline $\begin{array}{l}\text { Bypass time (min), } \\
\text { mean (range) }\end{array}$ & $144(0-255)$ & $151(0-249)$ & $149(0-255)$ \\
\hline $\begin{array}{l}\text { Aortic crossclamp } \\
\text { time (min), } \\
\text { mean (range) }\end{array}$ & $49(0-107)$ & $76(0-124)$ & $68(0-124)$ \\
\hline
\end{tabular}


TABLE 2. Patients' clinical diagnoses and corresponding operative procedures (in parentheses)

Diagnosis

No. of patients

Biventricular heart defects

Coarctation of the aorta and hypoplastic aortic arch \pm VSD (arch repair \pm VSD closure)

D-transposition of the great arteries with intact ventricular septum (arterial switch)

Truncus arteriosus (complete repair of truncus)

Double-outlet right ventricle with pulmonary stenosis/atresia (complete biventricular repair)

Total anomalous pulmonary venous connection (complete repair)

Pulmonary atresia/VSD (complete biventricular repair)

Interrupted aortic arch with aortopulmonary window (complete repair)

Complete atrioventricular septal defect (complete repair)

VSD and partial anomalous pulmonary venous connection (complete repair)

Dilated cardiomyopathy (heart transplantation)

Total

Single-ventricle heart defects

Unbalanced atrioventricular septal defect and heterotaxy (stage 1 Norwood procedure)

Hypoplastic left heart syndrome (stage 1 Norwood procedure)

Tricuspid atresia with hypoplastic aortic arch (arch repair and aortopulmonary shunt)

Aortic atresia (stage 1 Norwood procedure)

Double-outlet right ventricle with hypoplastic left ventricle (stage 1 Norwood procedure)

Double-inlet left ventricle (stage 1 Norwood procedure)

Total

$V S D$, Ventricular septal defect.

Regarding recovery, the decrease in cerebral $\mathrm{rSO}_{2}$ values observed in the biventricular group stabilized shortly after chest closure, whereas the negative trend was persistent at +24 hours in the single-ventricle group.

With respect to somatic $\mathrm{rSO}_{2}$ values in the biventricular and single-ventricle groups (Figure 4), values were unchanged after sternal closure in both the biventricular $(P=.11,1$-way ANOVA $)$ and single-ventricle $(P=.06$, 1-way ANOVA) groups, although lower $\mathrm{rSO}_{2}$ values were noted at selected time points ( -6 hours vs +6 hours) by using the paired $t$ test. Regarding recovery, somatic $\mathrm{rSO}_{2}$ values

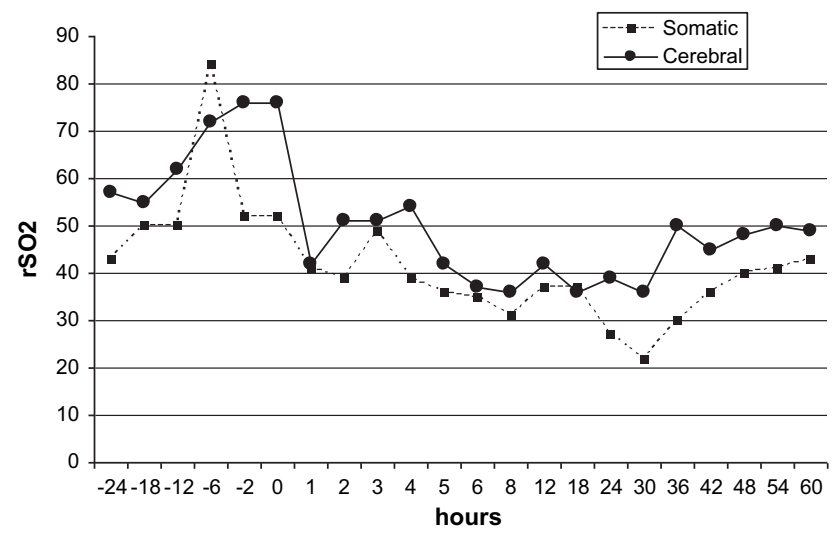

FIGURE 1. Changes over time in cerebral and somatic regional oxygen saturation $\left(\mathrm{rSO}_{2}\right)$ values in a neonate with single-ventricle circulation at the time of delayed sternal closure. Cerebral and somatic regional oxygen saturation values decrease after chest closure (at 0 hours) caused by low cardiac output and improve after sternal reopening approximately 30 hours later. recovered at +4 hours after chest closure in the biventricular group, whereas recovery occurred later $(+18$ hours) in the single-ventricle group.

Table 3 summarizes changes in $\mathrm{rSO}_{2}$ values and key physiologic parameters before and after chest closure. All preclosure measurements were pooled and compared with pooled postclosure measurements. Statistical comparisons were made by using the paired $t$ test.

With respect to changes in key physiologic parameters over time (Figure 5), we found that although mean blood pressure and inotrope scores were unchanged over time, heart rate and left atrial pressure increased after chest closure. A mild and transient decrease in $\mathrm{pH}$ and increase in base deficit were also noted, with normalization of these parameters occurring at approximately +6 hours after closure. The levels of $\mathrm{PaO}_{2}$ and $\mathrm{PCO}_{2}$ were unaffected by chest closure, although positive-pressure ventilation was increased (higher $\Delta \mathrm{P}$ ) after chest closure, suggesting a decrease in total lung compliance.

\section{DISCUSSION}

The primary focus of this investigation was to establish the role of cerebral and somatic $\mathrm{rSO}_{2}$ monitoring in detecting changes in hemodynamic performance after delayed sternal closure in children undergoing congenital heart surgery. The major findings of this study were that (1) the decrease in hemodynamic performance after delayed sternal closure was mild and transient, as suggested by changes in left atrial pressure, base deficit, and lactate levels, which normalized 6 to 12 hours after chest closure, in the 
NIRS Brain - ALL

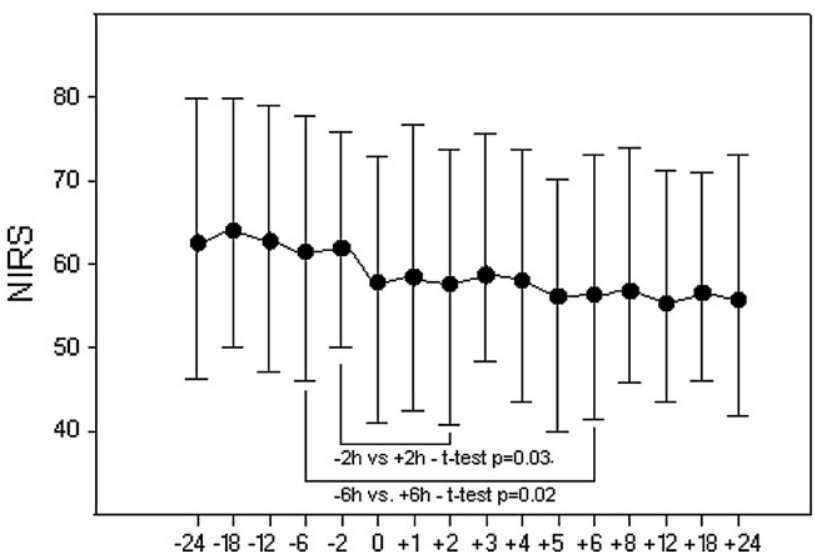

NIRS Somatic - ALL

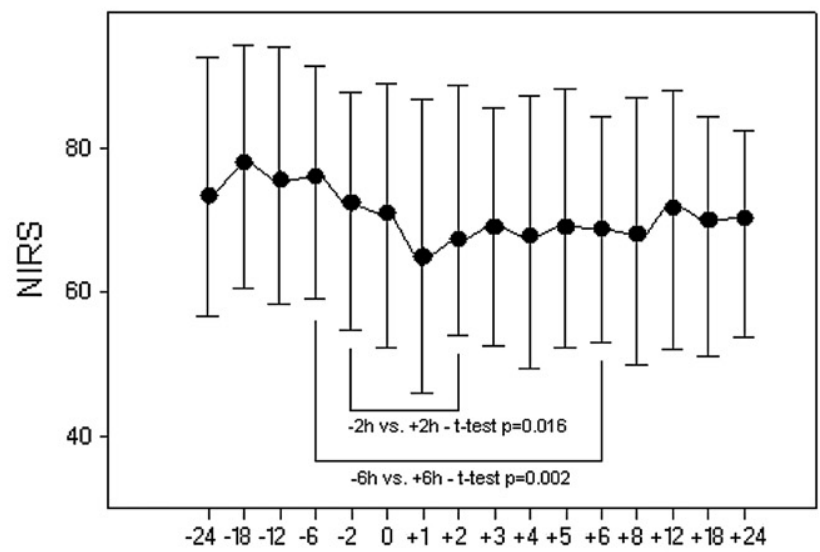

FIGURE 2. Trends in cerebral and somatic regional oxygen saturation values in all patients before and after sternal closure. The 0 on the $x$-axis (time in hours $)$ corresponds to the time of chest closure. Cerebral $(P=.02$, analysis of variance $)$ and somatic $(P=.01$, analysis of variance $)$ regional oxygen saturation values decreased after delayed sternal closure. The paired $t$ test was performed to compare data at -2 hours versus +2 hours and -6 hours versus +6 hours. $N I R S$, Near-infrared spectroscopy.

presence of unchanged inotropic requirement and hourly urine output; (2) cerebral and somatic $\mathrm{rSO}_{2}$ values decreased after delayed sternal closure; (3) somatic $\mathrm{rSO}_{2}$ values returned to preclosure levels earlier in the biventricular group than in the single-ventricle group; and (4) cerebral $\mathrm{rSO}_{2}$ values remained decreased after sternal closure with no evidence of return to preclosure levels during the observation period.

Detection of cerebral hypoxia is important to reduce the risk of adverse neurologic outcomes in children with congenital heart disease. ${ }^{7}$ Cyanotic children with singleventricle physiology might be especially vulnerable to cerebral hypoperfusion because they are hypoxemic and have limited cardiac reserve. ${ }^{9,10}$ Clinically, cerebral $\mathrm{rSO}_{2}$ monitoring with algorithms for interventions have been proposed as a tool to reduce the incidence of postoperative neurologic complications in congenital heart surgery. ${ }^{7}$ Other end-organ damage is also a known complication of patients undergoing congenital heart surgery. Because delayed sternal closure can affect cardiac output, renal hypoperfusion during this period can have an additive detrimental effect on kidney function and postoperative morbidity. Previous clinical studies have shown that cerebral and somatic $\mathrm{rSO}_{2}$ values can be used as surrogate indicators of central and cerebral venous oxygen saturation., As previous studies have suggested, absolute numeric values of $\mathrm{rSO}_{2}$ are of less importance than trends in $\mathrm{rSo}_{2}$ over time. ${ }^{10-12}$
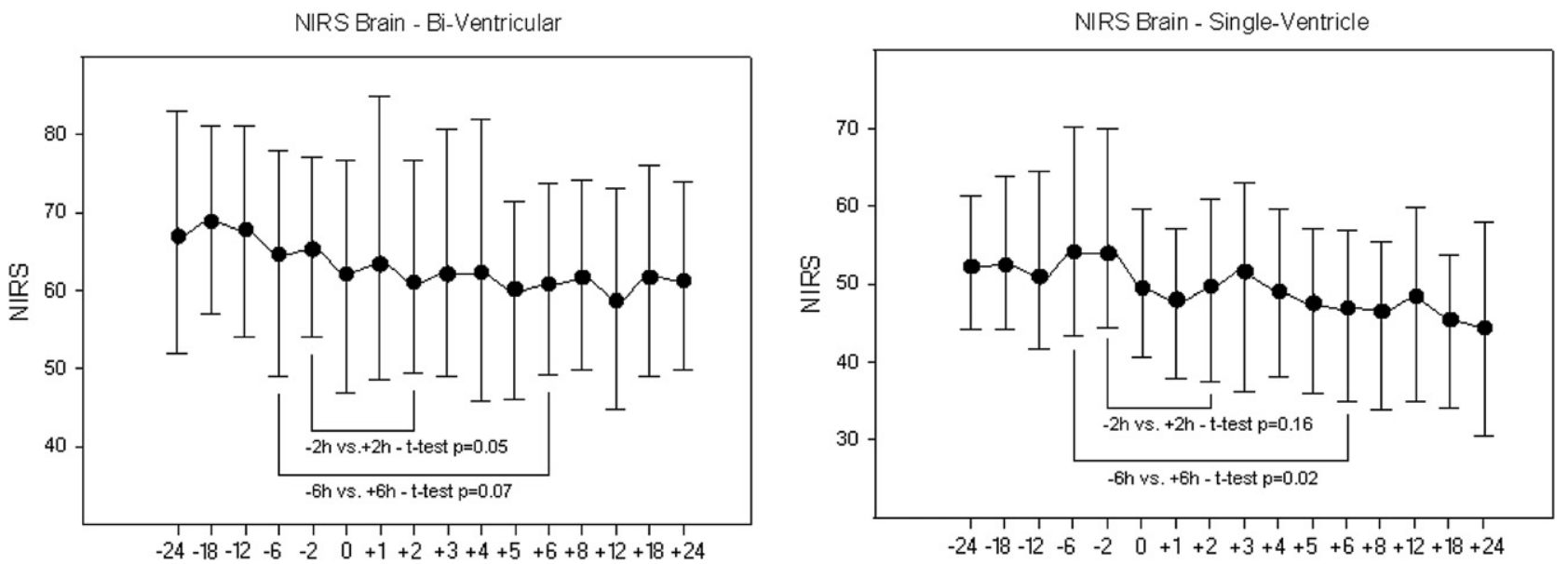

FIGURE 3. Trends in cerebral regional oxygen saturation values in the biventricular and single-ventricle groups before and after sternal closure. The 0 on the $x$-axis (time in hours) corresponds to the time of chest closure. Cerebral regional oxygen saturation values decreased after sternal closure in the biventricular group $(P=.04$, analysis of variance) but not in the single-ventricle group $(P=.2$, analysis of variance). The paired $t$ test was performed to compare data at -2 hours versus +2 hours and -6 hours versus +6 hours. NIRS, Near-infrared spectroscopy. 
NIRS Somatic - Bi-Ventricular

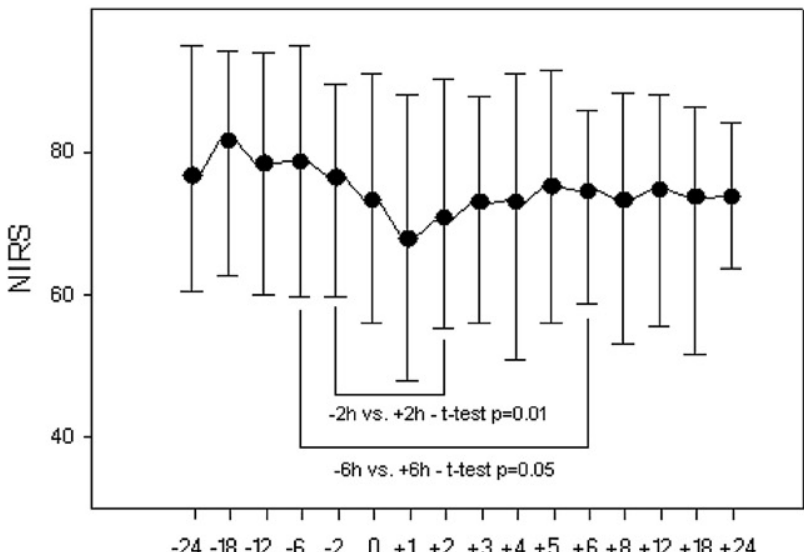

NIRS Somatic - Single-Ventricle

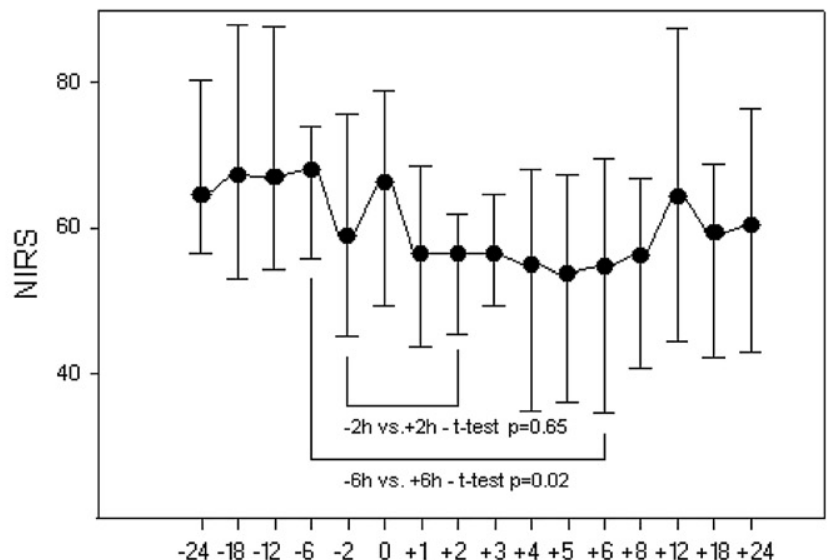

FIGURE 4. Trends in somatic regional oxygen saturation values in the biventricular and single-ventricle groups before and after sternal closure. The 0 on the $x$-axis (time in hours) corresponds to the time of chest closure. As determined by using analysis of variance, there was no significant change in somatic regional oxygen saturation values in the biventricular $(P=.11)$ and single-ventricle $(P=.06)$ groups. The paired $t$ test was performed to compare data at -2 hours versus +2 hours and -6 hours versus +6 hours. NIRS, Near-infrared spectroscopy.

The findings of our study are similar to those of Tabbutt and colleague, ${ }^{1}$ showing significant increases in left atrial pressure and heart rate in combination with lower arterial $\mathrm{pH}$ and mild lactate acidosis after delayed sternal closure, which is overall suggestive of a decrease in hemodynamic performance after sternal closure. However, in our patients the magnitude of such a decrease seemed modest, as suggested by preservation of physiologic parameters, such as

TABLE 3. Changes of physiologic variables before and after sternal closure

\begin{tabular}{|c|c|c|c|c|c|c|c|c|c|}
\hline \multirow[b]{2}{*}{ Variable } & \multicolumn{3}{|c|}{ Single-ventricle group } & \multicolumn{3}{|c|}{ Biventricular group } & \multicolumn{3}{|c|}{ All patients } \\
\hline & Before & After & $t$ Test & Before & After & $t$ Test & Before & After & $t$ Test \\
\hline \multicolumn{10}{|l|}{ NIRS } \\
\hline NIRS, brain $(\%)$ & $52.7 \pm 8.8$ & $47.7 \pm 8.2$ & $P<.001$ & $66.7 \pm 10.4$ & $61.3 \pm 10.6$ & $P<.001$ & $62.4 \pm 11.8$ & $56.9 \pm 11.8$ & $P<.001$ \\
\hline NIRS, somatic $(\%)$ & $65.3 \pm 11$ & $57.3 \pm 11.1$ & $P<.001$ & $78.4 \pm 11.2$ & $73 \pm 12.2$ & $P<.001$ & $75.1 \pm 12.5$ & $68.8 \pm 13.8$ & $P<.001$ \\
\hline \multicolumn{10}{|l|}{ Hemodynamic variables } \\
\hline $\mathrm{LAP}(\mathrm{mm} \mathrm{Hg})$ & $9.2 \pm 3.7$ & $11.3 \pm 3.6$ & $P=.003$ & $7.8 \pm 3.2$ & $8.8 \pm 2.7$ & $P=.01$ & $8.2 \pm 3.4$ & $9.5 \pm 3.2$ & $P=.04$ \\
\hline $\mathrm{CVP}(\mathrm{mm} \mathrm{Hg})$ & $13.1 \pm 6.9$ & $13.1 \pm 3.5$ & $P=.57$ & $10 \pm 2.9$ & $10.3 \pm 3.5$ & $P=.44$ & $10.9 \pm 4.7$ & $11.2 \pm 3.8$ & $P=.25$ \\
\hline Systolic BP (mm Hg) & $80 \pm 16.3$ & $79.4 \pm 15.1$ & $P=.96$ & $79.2 \pm 16.1$ & $80.7 \pm 14.4$ & $P=.23$ & $79.5 \pm 16.2$ & $80.3 \pm 14.6$ & $P=.34$ \\
\hline Diastolic BP (mm Hg) & $45.3 \pm 7.7$ & $46.4 \pm 9.5$ & $P=.58$ & $47 \pm 9.1$ & $49.6 \pm 11.1$ & $P=.06$ & $46.5 \pm 8.7$ & $45.6 \pm 10.6$ & $P=.07$ \\
\hline Mean BP (mm Hg) & $58 \pm 11.4$ & $58.8 \pm 10.5$ & $P=.56$ & $59 \pm 10.9$ & $59.9 \pm 10.4$ & $P=.29$ & $58.7 \pm 11$ & $59.5 \pm 10.4$ & $P=.24$ \\
\hline Heart rate (beats/min) & $165.4 \pm 12.2$ & $170.3 \pm 124$ & $P=.015$ & $154.4 \pm 15.2$ & $158.8 \pm 21.5$ & $P<.001$ & $157.8 \pm 15.2$ & $162.5 \pm 19.8$ & $P<.001$ \\
\hline \multicolumn{10}{|l|}{ Metabolic variables } \\
\hline $\mathrm{pH}$ & $7.39 \pm 0.06$ & $7.36 \pm 0.07$ & $P=.004$ & $7.42 \pm 0.06$ & $7.44 \pm 0.06$ & $P=.01$ & $7.41 \pm 0.06$ & $7.41 \pm 0.08$ & $P=.68$ \\
\hline Base deficit & $1.7 \pm 4.8$ & $-0.2 \pm 3.4$ & $P=.02$ & $2.2 \pm 3.9$ & $2.4 \pm 4.2$ & $P=.7$ & $2.1 \pm 4.2$ & $1.5 \pm 4.1$ & $P=.17$ \\
\hline Lactic acid (mM/dL) & $2.2 \pm 1$ & $3.1 \pm 2.6$ & $P=.2$ & $1.4 \pm 1.2$ & $1.7 \pm 0.8$ & $P=.97$ & $1.9 \pm 1.1$ & $2.7 \pm 2.1$ & $P=.025$ \\
\hline Hematocrit $(\%)$ & $42.5 \pm 4.7$ & $44.2 \pm 5.1$ & $P=.06$ & $41.3 \pm 5.5$ & $41 \pm 4.8$ & $P=.69$ & $41.7 \pm 5.3$ & $42.1 \pm 5.2$ & $P=.46$ \\
\hline Urine output $(\mathrm{mL} / \mathrm{d})$ & $433 \pm 154$ & $351 \pm 124$ & $P=.18$ & $416 \pm 214$ & $488 \pm 257$ & $P=.19$ & $422 \pm 195$ & $445 \pm 231$ & $P=.57$ \\
\hline Inotrope score* & $12.4 \pm 3.1$ & $13.8 \pm 2.9$ & $P=.007$ & $9.7 \pm 3.2$ & $10.1 \pm 3.7$ & $P=.49$ & $10.6 \pm 3.9$ & $11.3 \pm 3.8$ & $P=.09$ \\
\hline \multicolumn{10}{|l|}{ Respiratory variables } \\
\hline $\mathrm{PaO}_{2}(\mathrm{~mm} \mathrm{Hg})$ & $40.8 \pm 4.2$ & $39.6 \pm 4.3$ & $P=.13$ & $118.8 \pm 58$ & $117.7 \pm 47$ & $P=.66$ & $96.8 \pm 60.3$ & $93.3 \pm 53.5$ & $P=.56$ \\
\hline $\mathrm{PaCO}_{2}(\mathrm{~mm} \mathrm{Hg})$ & $44.1 \pm 6.6$ & $45.1 \pm 7.1$ & $P=.42$ & $41.9 \pm 6.7$ & $40.25 \pm 6.8$ & $P=.03$ & $42.6 \pm 6.8$ & $41.8 \pm 7.3$ & $P=.21$ \\
\hline Oxygen saturation $(\%)$ & $76.8 \pm 5.7$ & $75.1 \pm 7.5$ & $P=.14$ & $97.1 \pm 3.2$ & $97.5 \pm 3.7$ & $P=.007$ & $90.9 \pm 10.2$ & $90.4 \pm 11.6$ & $P=.29$ \\
\hline $\mathrm{FIO}_{2}(\%)$ & $40.1 \pm 15.6$ & $45.1 \pm 17.8$ & $P=.07$ & $44.7 \pm 10.7$ & $47.8 \pm 10.7$ & $P<.001$ & $43.1 \pm 12.5$ & $47.3 \pm 17.2$ & $P<.001$ \\
\hline$\Delta \mathrm{P}\left(\mathrm{cm} \mathrm{H}_{2} \mathrm{O}\right)$ & $18.6 \pm 3.9$ & $22.5 \pm 4.9$ & $P<.001$ & $18.2 \pm 3.5$ & $19.8 \pm 3.9$ & $P<.001$ & $18.3 \pm 3.6$ & $20.7 \pm 4.4$ & $P<.001$ \\
\hline Tidal volume $(\mathrm{mL})$ & $40.7 \pm 12.1$ & $41.6 \pm 7.9$ & $P=.18$ & $47.7 \pm 20.1$ & $46.5 \pm 19.6$ & $P=.66$ & $45.5 \pm 18.2$ & $45.1 \pm 17.1$ & $P=.79$ \\
\hline
\end{tabular}

Data are expressed as means \pm standard deviations. All preclosure and postclosure measurements were grouped together and compared by using the paired $t$ test.

$N I R S$, Near-infrared spectroscopy; $L A P$, left atrial pressure; $C V P$, central venous pressure; $B P$, blood pressure; $\mathrm{FIO}_{2}$, fraction of inspired oxygen; $\triangle P$, change in pressure.

$*$ Inotrope score $=($ Dopamine infusion rate $\times 1)+($ Milrinone infusion rate $\times 10)+($ Epinephrine infusion rate $\times 100)$. 

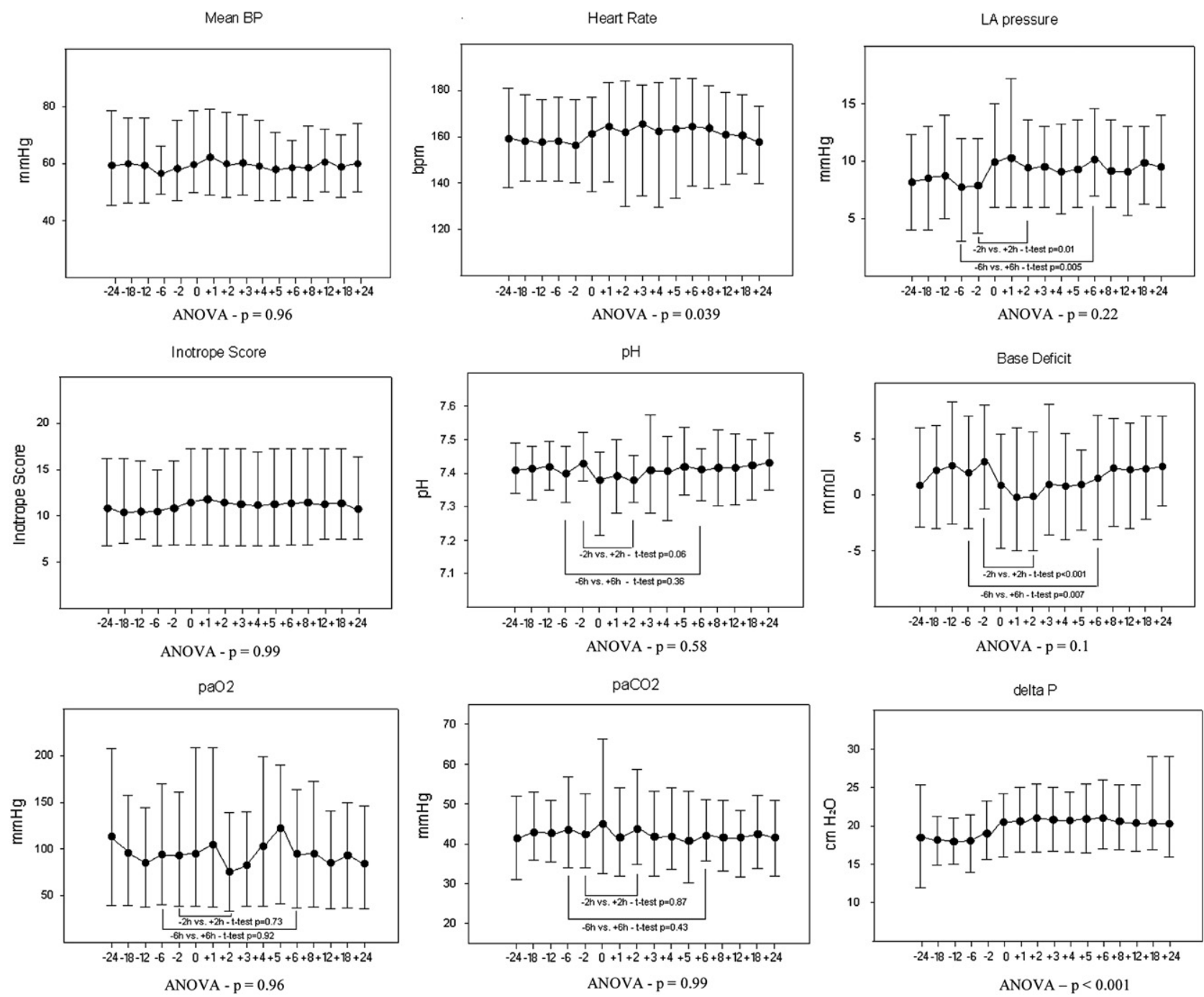

FIGURE 5. Changes over time in key physiologic parameters. The 0 on the $x$-axis (time in hours) corresponds to the time of chest closure. The paired $t$ test was performed in selected cases to compare data at -2 hours versus +2 hours and -6 hours versus +6 hours. $B P$, Blood pressure; $L A$, left atrial; $A N O V A$, analysis of variance; delta $P$, change in pressure.

systemic arterial pressure and hourly urine output, in the face of unchanged inotrope scores. The corresponding decrease in cerebral and somatic $\mathrm{rSO}_{2}$ values after sternal closure noted in our children was statistically significant when all children in the study group were analyzed together (Figure 2). However, when the biventricular and single-ventricle groups were analyzed separately, cerebral $\mathrm{rSO}_{2}$ values were lower after sternal closure in the biventricular group but not in the single-ventricle group by using 1-way ANOVA, although a difference was found in this group between -6 hours and +6 hours from chest closure (paired $t$ test, Figure 3). This finding might seem surprising because the single-ventricle group would be expected to be more vulnerable to a decrease in $\mathrm{rSO}_{2}$ values after sternal closure because of limited cardiac output reserve compared with patients with biventricular physiology. In terms of absolute cerebral $\mathrm{rSO}_{2}$ numeric values in the single-ventricle group, our data are consistent with those of $\mathrm{Li}$ and associates, ${ }^{13}$ who investigated trends in cerebral $\mathrm{rSO}_{2}$ values in neonates with hypoplastic left heart syndrome after the stage 1 Norwood procedure. It is possible that the relatively small number of children in the single-ventricle group and the considerable data variability might have limited our ability to detect a statistically significant difference using ANOVA, although we found a difference when comparing preclosure and postclosure numeric values at selected time points, as shown in Figure 3 and Table 3. Significant interindividual and intraindividual variability in $\mathrm{rSO}_{2}$ values, which was common in our study and in others, ${ }^{13}$ can limit ANOVA in a small study group. Of importance was the fact that cerebral $\mathrm{rSO}_{2}$ values seemed to continue to decrease late after sternal closure in the single-ventricle group, with no evidence of recovery at +24 hours after closure (Figure 2). In contrast, somatic $\mathrm{rSO}_{2}$ values seemed to normalize after chest closure, 
although this occurred earlier in the biventricular group versus the single-ventricle group (Figure 3). At present, the phenomenon of a lack of cerebral $\mathrm{rSO}_{2}$ recovery after chest closure remains incompletely understood. In our single-ventricle group changes in $\mathrm{rSO}_{2}$ values occurred without corresponding changes in arterial oxygenation. This would suggest that changes in cerebral $\mathrm{rSO}_{2}$ values were caused by a decrease in cerebral blood flow, an increase in brain metabolic activity after chest closure, or both. ${ }^{10}$ The fact that neuromuscular blockade was routinely discontinued after chest closure could have played a role in increasing cerebral metabolic activity, increasing cerebral oxygen demand, and decreasing $\mathrm{rSO}_{2}$ values. However, this must be accompanied by some form of cardiac insufficiency that would normally compensate for this increase in metabolic rate, therefore leading to a relative mismatch in cerebral oxygen supply and demand and maintaining lower cerebral $\mathrm{rSO}_{2}$ values.

\section{LIMITATIONS}

We acknowledge that our study has several limitations. The pitfalls of $\mathrm{rSO}_{2}$ monitoring have been investigated widely. ${ }^{3,4,10,14}$ Weaknesses of our study also include the retrospective nature of the review, the variability of the physiologic and $\mathrm{rSO}_{2}$ data, and the small size of the study group. Also, the fact that a control group was not available (in our program most neonates, the dominant group in the study, are managed with delayed sternal closure) might be viewed as a limitation, although in our study each patient served as his or her own control subject when comparing preclosure versus postclosure parameters. Additional limitations relate to limited data completeness for certain biochemical markers not available at all time points (lactate levels). Other weaknesses involve the potential effect of other physiologic changes on $\mathrm{rSO}_{2}$ values (ie, possible changes in endogenous catecholamines over time) or pharmacologic changes (ie, discontinuation of neuromuscular blockade after chest closure), which our study was not able to address.

\section{CONCLUSIONS}

Notwithstanding these limitations, we can conclude that cerebral and somatic $\mathrm{rSO}_{2}$ values decrease after delayed sternal closure in children undergoing complex congenital heart surgery. In our study $\mathrm{rSO}_{2}$ changes were found to be associated with a modest and transient decrease in hemodynamic performance, as indirectly suggested by concomitant changes in other physiologic indicators of cardiac performance. The decrease in somatic $\mathrm{rSO}_{2}$ values seemed to normalize earlier in the biventricular group compared with values seen in the single-ventricle group, whereas no meaningful recovery was observed for cerebral $\mathrm{rSO}_{2}$ values after chest closure. Although these trends require further investigation, it is possible that concomitant physiologic or pharmacologic changes, such as discontinuation of neuromuscular blockade and marginal cardiac output reserve leading to an imbalance in cerebral oxygen supply and demand, can explain, at least in part, the lack of recovery of cerebral $\mathrm{rSO}_{2}$ compared with somatic $\mathrm{rSO}_{2}$ values in the postclosure period. Based on these observations, we have incorporated $\mathrm{rSO}_{2}$ monitoring into our practice and use this technology in combination with other indirect markers of cardiac output and tissue perfusion when making clinical decisions at the time of chest closure.

\section{References}

1. Tabbutt S, Duncan BW, McLaughlin D, Wessel DL, Jonas RA, Laussen PC. Delayed Sternal Closure after cardiac operations in a pediatric population. J Thorac Cardiovasc Surg. 1997;113:886-93.

2. Iyer RS, Jacobs JP, de Leval MR, Stark J, Elliott MJ. Outcomes after delayed sternal closure in pediatric heart operations: a 10-year experience. Ann Thorac Surg. 1997;63:489-91.

3. Andropoulos DB, Stayer SA, Diaz LK, Ramamoorthy C. Neurological monitoring for congenital heart surgery. Anesth Analg. 2004;99:1365-75.

4. McQuillen PS, Nishimoto MS, Bottrell CL, Fineman LD, Hamrick SE, Glidden DV, et al. Regional and central venous oxygen saturation monitoring following pediatric cardiac surgery: concordance and association with clinical variables. Pediatr Crit Care Med. 2007;8:154-60.

5. Tortoriello TA, Stayer SA, Mott AR, McKenzie ED, Fraser CD, Andropoulos DB, et al. A noninvasive estimation of mixed venous oxygen saturation using near-infrared spectroscopy by cerebral oximetry in pediatric cardiac surgery patients. Paediatr Anaesth. 2005;15:495-503.

6. Daubeney PEF, Pilkington SN, Janke E, Charlton GA, Smith BC, Webber SA. Cerebral oxygenation measured by near-infrared spectroscopy: comparison with jugular bulb oximetry. Ann Thorac Surg. 1996;61:930-4.

7. Austin EH 3rd, Edmonds HL Jr, Auden SM, Seremet V, Niznik G, Sehic A, et al. Benefit of neurophysiologic monitoring for pediatric cardiac surgery. J Thorac Cardiovasc Surg. 1997;114:707-17.

8. Kurth CD, Steven JL, Montenegro L, Watzman HM, Gaynor JW, Spray TL, et al. Cerebral oxygen saturation before congenital heart surgery. Ann Thorac Surg. 2001;72:187-92.

9. Hoffman GM, Stuth EA, Jaquiss RD, Vanderwal PL, Staudt SR, Troshynski TJ, et al. Changes in cerebral and somatic oxygenation during stage 1 palliation of hypoplastic left heart syndrome using continuous regional cerebral perfusion. $J$ Thorac Cardiovasc Surg. 2004;127:223-33.

10. Ricci M, Lombardi P, Schultz S, Galindo A, Coscarella E, Vasquez A, et al. Near-Infrared spectroscopy to monitor cerebral oxygen saturation in single-ventricle physiology. J Thorac Cardiovasc Surg. 2006;131: 395-402.

11. Kusaka T, Isobe K, Nagano K, Okubo K, Yasuda S, Kondo M, et al. Quantification of cerebral oxygenation by full-spectrum near-infrared spectroscopy using a two-point method. Compar Biochem Physiol. 2002;132: 121-32.

12. Kurth CD, Levy WJ, McCann J. Near-infrared spectroscopy cerebral oxygen saturation thresholds for hypoxia-ischemia in piglets. J Cereb Blood Flow Metab. 2002;22:335-41.

13. Li J, Zhang G, Holtby H, Guerguerian AM, Cai S, Humpl T, et al. The influence of systemic hemodynamics and oxygen transport on cerebral oxygen saturation in neonates after the Norwood procedure. J Thorac Cardiovasc Surg. 2008;135: 83-90.

14. Watzman HM, Kurth CD, Montenegro LM. Arterial and venous contributions to near-infrared cerebral oximetry. Anesthesiology. 2000;93:947-53. 